\title{
Word deafness: one hundred years later
}

\author{
ARON S BUCHMAN,* DAVID C GARRON, $\dagger$ JUDITH E TROST-CARDAMONE, \\ MELVIN D WICHTER,§ MICHAEL SCHWARTZ§
}

From the Department of Neurological Sciences* and Department of Psychology and Social Sciences, $\dagger$ Rush-Presbyterian-St. Lukes Medical Center, Chicago, Illinois, the Department of Communicative Disorders, $\ddagger$ California State University, Northridge, Northridge, California, the Department of Neurology, $\S$ Christ Hospital, Oaklawn, Illinois, USA

SUMMARY Since its original description the diagnosis of word deafness has been greatly expanded. Confusion has arisen with regard to the usage of the related terms pure word deafness, auditory agnosia, and cortical deafness. Three new cases of word deafness are presented including one case with CT and necropsy correlation. These cases are compared with 34 previously reported cases of various cortical auditory disorders. Our review establishes that patients with word deafness who have had formal testing of linguistic and non-linguistic sound comprehension and musical abilities always demonstrated a more pervasive auditory agnosia. Despite the spectrum of auditory deficits and associated language abnormalities, patients with word deafness share common features including aetiology, pathology, clinical presentation and course. These common features justify inclusion of heterogeneous cortical auditory disorders under the rubric of word deafness. Despite some limitations the term "word deafness" should be retained for this syndrome, since inability to comprehend spoken words is the most distinctive clinical deficit. Word deafness is most frequently caused by cerebrovascular accidents of presumed cardiac embolisation, with bitemporal corticosubcortical lesions. The sequence of cerebral injury is not predictive of resulting auditory deficits. Impairment of musical abilities parallels the severity of the auditory disorder.

In 1885 , Lichtheim described the syndrome of word deafness as a rare disorder characterised by defective comprehension, repetition, and writing to dictation. ${ }^{1}$ Defective repetition differentiates this disorder from a transcortical sensory aphasia, and preservation of reading, writing and spontaneous speech differentiates it from Wernicke's aphasia. ${ }^{2} 3$ Patients are not deaf and may have normal or near normal pure tone audiometric findings.

Since its original description, the diagnosis of word deafness has been greatly expanded. Confusion has arisen with regard to the usage of the related terms pure word deafness, auditory agnosia, and cortical deafness. Clinically there is indeed a relatively rare but behaviourally distinct subgroup of patients whose marked disparity between performance in speech comprehension and repetition on the one hand, and

Address for reprint requests: Aron S Buchman, MD, RushPresbyterian-St. Lukes Medical Center, Professional Building Room 915, 1753 West Harrison Street, Chicago, Illinois 60612, USA.

Received 30 May 1985 and revised form 1 October 1985. Accepted 16 October 1985 other linguistic functions on the other hand, distinguishes them from aphasic patients. In the latter group, the linguistic impairment typically cuts across all or most modalities. In contrast non-aphasic patients with cortical auditory disorders demonstrate overall preservation of non-auditory language functions. Table 1 summarises this discrepancy between auditory and non-auditory linguistic behaviour for the three common varieties of cortical auditory disorders and presents a conceptual framework for viewing their clinical features. Despite the differing labels, these cortical auditory disorders present similar behavioural clusters. The most divergent feature is impaired hearing sensitivity in patients with cortical deafness.

A review of the literature of cortical auditory disorders establishes that no patients previously reported with word deafness who have had formal testing of linguistic and non-linguistic sound comprehension and musical abilities have had "pure" word deafness. All patients always demonstrated a more pervasive auditory agnosia ranging from complete deafness to more subtle auditory processing disturbances. It is our 
Table 1 Classification of cortical auditory disorders*

\begin{tabular}{|c|c|c|c|}
\hline & $\begin{array}{l}\text { Pure word } \\
\text { deafness }\end{array}$ & $\begin{array}{l}\text { Auditory } \\
\text { agnosia }\end{array}$ & $\begin{array}{l}\text { Cortical } \\
\text { deafness }\end{array}$ \\
\hline $\begin{array}{l}\text { 1. Speech } \\
\text { comprehension }\end{array}$ & + & + & + \\
\hline 2. Speech repetition & + & + & + \\
\hline $\begin{array}{l}\text { 3. Non-linguistic } \\
\text { auditory comp. }\end{array}$ & - & + & + \\
\hline 4. Hearing sensitivity & - & - & + \\
\hline 5. Spontaneous speech & - & - & - \\
\hline $\begin{array}{l}\text { 6. Reading } \\
\text { comprehension }\end{array}$ & - & - & - \\
\hline 7. Written language & - & - & - \\
\hline
\end{tabular}

*Based on Benson FD, $1972^{2}$ and Oppenheimer DR and Newcombe F, 1978. ${ }^{30}$

Key: $+=$ impaired; $-=$ normal

Table 2 Results from selected subsets of the Western Aphasia Battery for Patient 1

\begin{tabular}{|c|c|c|}
\hline Subtest & Score & $\begin{array}{l}\text { Maximum } \\
\text { possible } \\
\text { score }\end{array}$ \\
\hline \multicolumn{3}{|l|}{ Spontaneous speech } \\
\hline Functional content & 8 & 10 \\
\hline Fluency & 10 & 10 \\
\hline \multicolumn{3}{|l|}{ Auditory verbal comprehension } \\
\hline $\begin{array}{l}\text { Yes/No Questions } \\
\text { Auditory word recognition }\end{array}$ & $51^{0,60^{*}}$ & $\begin{array}{l}60 \\
60\end{array}$ \\
\hline Sequential commands & $0,66^{*}$ & 80 \\
\hline Repetition (Words, Phrases, Sentences) & 0 & 100 \\
\hline \multicolumn{3}{|l|}{ Naming } \\
\hline Object naming & $60 \dagger$ & 60 \\
\hline Word fluency & CNT $\ddagger$ & - \\
\hline Sentence completion & $0,10^{*}$ & 10 \\
\hline Responsive speech & $0,10^{*}$ & \\
\hline \multicolumn{3}{|l|}{ Reading } \\
\hline \multicolumn{2}{|l|}{ Reading comprehension of } & 40 \\
\hline Reading commands & 17 & 20 \\
\hline Written word stimulus/Object & 6 & 6 \\
\hline \multicolumn{3}{|l|}{$\begin{array}{l}\text { matching } \\
\text { Written word stimulus/Picture }\end{array}$} \\
\hline \multicolumn{3}{|l|}{$\begin{array}{l}\text { matcning } \\
\text { Picture stimulus/Written word }\end{array}$} \\
\hline & 6 & 6 \\
\hline \multicolumn{3}{|l|}{ Spoken word/Written word } \\
\hline Letter discrimination & 6 & 6 \\
\hline Spelled word recognition (oral) & 0 & 6 \\
\hline Spelled (orally presented words) & 0 & 6 \\
\hline \multicolumn{3}{|l|}{ Writing } \\
\hline Writing on request (name, address) & & \\
\hline Written output (picture description) & 24 & 34 \\
\hline Writing to dictation & CNT & - \\
\hline Writing visually presented words & 10 & 10 \\
\hline Alphabet & $12 \cdot 5$ & $12 \cdot 5$ \\
\hline Numbers 0 to 20 & 10 & 10 \\
\hline Dictated letters and numbers & CNT & - \\
\hline Copying of words of a sentence & 10 & 10 \\
\hline
\end{tabular}

Key: *Adjusted score based on reading the stimulus items. tIncluded responses containing phonemic (literal) paraphasias. CNT-Could Not Test. ‡Poor patient cooperation.
Table 3 Results from selected subsets of the Boston Diagnostic Aphasia Examination for Patient 2

\begin{tabular}{|c|c|c|}
\hline$\overline{\text { Subtest }}$ & Score & $\begin{array}{l}\text { Maximum } \\
\text { possible } \\
\text { score }\end{array}$ \\
\hline \multicolumn{3}{|l|}{ Fluency } \\
\hline Articulation rating & 5 & 5 \\
\hline Phrase length & 5 & 7 \\
\hline Verbal agility & 6 & 7 \\
\hline \multicolumn{3}{|l|}{ Auditory comprehension } \\
\hline Word discrimination & 56 & 72 \\
\hline Commands & 5 & 15 \\
\hline Complex material & 0 & 12 \\
\hline \multicolumn{3}{|l|}{ Naming } \\
\hline Responsive naming & DNT & - \\
\hline Confrontation & 85 & 105 \\
\hline \multicolumn{3}{|l|}{ Oral reading } \\
\hline Word & 30 & 30 \\
\hline Sentence & 10 & 10 \\
\hline Repetition & CNT & - \\
\hline \multicolumn{3}{|l|}{ Automatised speech } \\
\hline Automatised sequences & 8 & 8 \\
\hline \multicolumn{3}{|l|}{ Reading comprehension } \\
\hline Word-picture matching & 10 & 10 \\
\hline Reading sentences, paragraphs & 7 & 10 \\
\hline \multicolumn{3}{|l|}{ Writing } \\
\hline Mechanics & 3 & 3 \\
\hline Narrative writing & 3 & 4 \\
\hline
\end{tabular}

Key: CNT—Could Not Test. DNT-Did Not Test.

thesis that despite the spectrum of auditory deficits and associated language abnormalities, patients with word deafness share common features including aetiology, pathology, clinical presentation and course. These common features justify inclusion of heterogeneous cortical auditory disturbances under the rubric of word deafness.

In the present report, three patients are presented, exemplifying the spectrum of auditory deficits and variable language dysfunction in word deafness. These patients are compared with 34 previously reported cases of cortical auditory disorders with specific reference to auditory comprehension deficits, language dysfunction and abnormalities of musical abilities (tables 4-6). ${ }^{14-37}$

\section{Case reports}

\section{Patient 1}

A 75-year-old right-handed female was admitted in December 1983, for depression, suicidal and paranoid ideation, and aggressive behaviour during the previous six to eight months. On the day of admission she had tried to climb out of the window of a moving car. She was acutely psychotic and threatened suicide. No visual or auditory hallucinations were described. Her past medical history included hypertension, congestive heart failure, and intermittent atrial fibrillation controlled with digoxin and diuretics.

The family described an episode lasting a few hours in 1981 when she was confused, combative and reported difficulty in hearing. In August 1982 she was hospitalised for a cerebrovascular accident, described as the sudden onset of hearing difficulties, confusion and an inability to recognise 


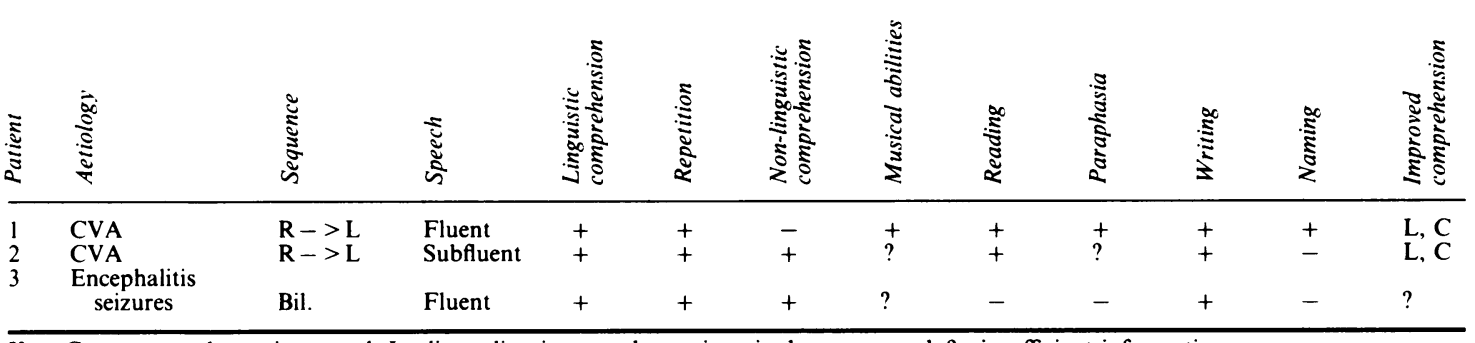

Key: C-contextual cues improved; L-lipreading improved; + -impaired; - - normal; ?-insufficient information.

her daughter. She was unable to understand spoken words but had no difficulty understanding written information. Neurological examination in 1982 was reported to be normal, except for paraphasic errors in otherwise fluent speech. An isotope scan was normal, but a CT scan of the head showed the right ventricle larger than the left and a nonenhancing area of right parietal lobe attenuation consistent with infarction. A repeat CT scan one week later revealed multiple small contrast-enhancing densities in the left temporo-occipital junction. An EEG showed focal left temporal slowing. Audiological evaluation revealed a symmetrical moderate to severe sloping sensorineural hearing loss that did not account for her speech comprehension

Table 5 Previous reports of word deafness

\begin{tabular}{|c|c|c|c|c|}
\hline$P t$ & Author & Year & Aetiology & Sequence \\
\hline 1 & Lichtheim $^{1}$ & 1885 & CVA & - \\
\hline 2 & Mills ${ }^{4}$ & 1891 & CVA & - \\
\hline 3 & Mott $^{5}$ & 1907 & CVA & $\mathbf{L}->\mathbf{R}$ \\
\hline 4 & Barrett $^{6}$ & 1910 & CVA & - \\
\hline 5 & Bramwell $^{7}$ & 1927 & CVA & $\mathbf{L}->\mathbf{R}$ \\
\hline 6 & Le Gros Clark et $a l^{8}$ & 1938 & CVA & $\mathbf{R}->\mathrm{L}$ \\
\hline 7 & Hemphill et $a l^{9}$ & 1940 & Trauma & - \\
\hline 8 & Reinhold $^{10}$ & 1950 & CVA & - \\
\hline 9 & Jones et $a l^{11}$ & 1952 & CVA & - \\
\hline 10 & Wohlfart et $a l^{12}$ & 1952 & CVA & - \\
\hline 11 & Ziegler $^{13}$ & 1952 & CVA & - \\
\hline 12 & Klein et $a l^{14}$ & 1956 & CVA & - \\
\hline 13 & Albert et $a l^{15}$ & 1957 & CVA & - \\
\hline 14 & Kliest ${ }^{16}$ & 1962 & CVA & - \\
\hline 15 & Tanaka et $a l^{17}$ & 1964 & CVA & 一 \\
\hline 16 & Jerger et $a l^{18}$ & 1969 & CVA & $\mathbf{L}->\mathbf{R}$ \\
\hline 17 & Albert et $a l^{19}$ & 1972 & CVA & $\mathbf{R}->\mathbf{L}$ \\
\hline 18 & Jerger et $a l^{20}$ & 1972 & CVA & $\mathbf{L}->\mathbf{R}$ \\
\hline & Kanshepolsky et $a l^{21}$ & 1973 & & \\
\hline 19 & Gazzaniga et $a l^{22}$ & 1973 & CVA & - \\
\hline 20 & Horenstein et $a l^{23}$ & 1973 & Trauma & 一 \\
\hline 21 & Nagafuchi et $a^{24}$ & 1973 & Surgery & 一 \\
\hline 22 & Denes $e t a l^{25}$ & 1975 & Seizure & - \\
\hline 23 & Goldstein $e t a l^{26}$ & 1975 & Encephalitis & - \\
\hline 24 & Saffran et $a l^{27}$ & 1976 & CVA & - \\
\hline 25 & Earnest et $a l^{28}$ & 1977 & CVA & $\mathbf{R}->\mathbf{L}$ \\
\hline 26 & Shoumaker et $a l^{29}$ & 1977 & ? seizure & - \\
\hline 27 & Oppenheimer et $a l^{30}$ & 1978 & CVA & $\mathbf{L}->\mathbf{R}$ \\
\hline 28 & Dalla et $a l^{31}$ & 1979 & CVA & $\mathbf{R}->\mathbf{L}$ \\
\hline 29 & Michel et al $^{32}$ & 1980 & CVA & - \\
\hline 30 & Parving $e t a l^{33}$ & 1980 & CVA & $\mathbf{L}->\mathbf{R}$ \\
\hline 31 & Kirshner et $a l^{34}$ & 1981 & CVA & $\overline{\mathbf{R}}->\mathbf{L}$ \\
\hline 32 & Auerbach et $a^{35}$ & 1982 & CVA & $\mathbf{L}->\mathbf{R}$ \\
\hline 33 & Doyle et $a l^{36}$ & 1982 & CVA & $\overline{\mathbf{R}}->\mathbf{L}$ \\
\hline 34 & Coslett et $a l^{37}$ & 1984 & CVA & $\mathbf{R}->\mathbf{L}$ \\
\hline
\end{tabular}

deficit. Speech discrimination could not be tested. There was no history of previous psychiatric illness. The family described the gradual onset of depression following her stroke.

On examination in December 1983, the patient was awake, alert and fully oriented. Neurological examination including visual fields was unremarkable except for the language dysfunction described below. Her medical evaluation included EKG and Holter monitor which demonstrated intermittent atrial fibrillation. Mild background slowing was seen on EEG. A CT scan of the head demonstrated an old large right temporal lobe and a smaller left posterior temporo-parietal infarction. A small lacunar infarction of the left anterior limb of the internal capsule and a deep enhancing left occipital infarction with moderate cortical atrophy were seen (fig 1).

Speech comprehension, repetition, and writing to dictation were impaired. The marked discrepancy between her impaired spoken language comprehension and speech repetition skills, and relatively preserved written skills, is easily observed from the test summary profile presented in table 2. Spontaneous speech output was normally fluent and grammatically intact, but contained both literal and semantic paraphasias which seemed to vary in frequency and which she occasionally attempted to correct. Paraphasias were most frequent in confrontation naming tasks and were evident in $79 \%$ of her error responses on the Boston Naming Test; most of these were phonemic or literal paraphasias. Although unable to comprehend connected speech, she was clearly auditorily responsive to speech and other auditory, non-speech stimuli, often stating, "I'm just not getting it", or "It all sounds like jabber to me". She was able to understand and repeat occasional spoken words and developed answers and sometimes whole conversations in response to what she assumed was being discussed. Comprehension of spoken language was improved by lip reading and contextual clues; this would appear to be reflected in her good performance in selecting an appropriate written word or displayed object to match a presented spoken word (subtests: Auditory Word Recognition; Spoken Word/Written Word Matching). Although reading comprehension was impaired, it was markedly superior to spoken language comprehension. The patient had a startle response to loud noises and seemed to hear most environmental sounds. She was able to identify $6 / 6$ non-speech environmental sounds by matching a written word describing the task, as in "clapping", to the environmental sound presented. Although she recognised familiar tunes and would hum correct melodies along with the exam- 


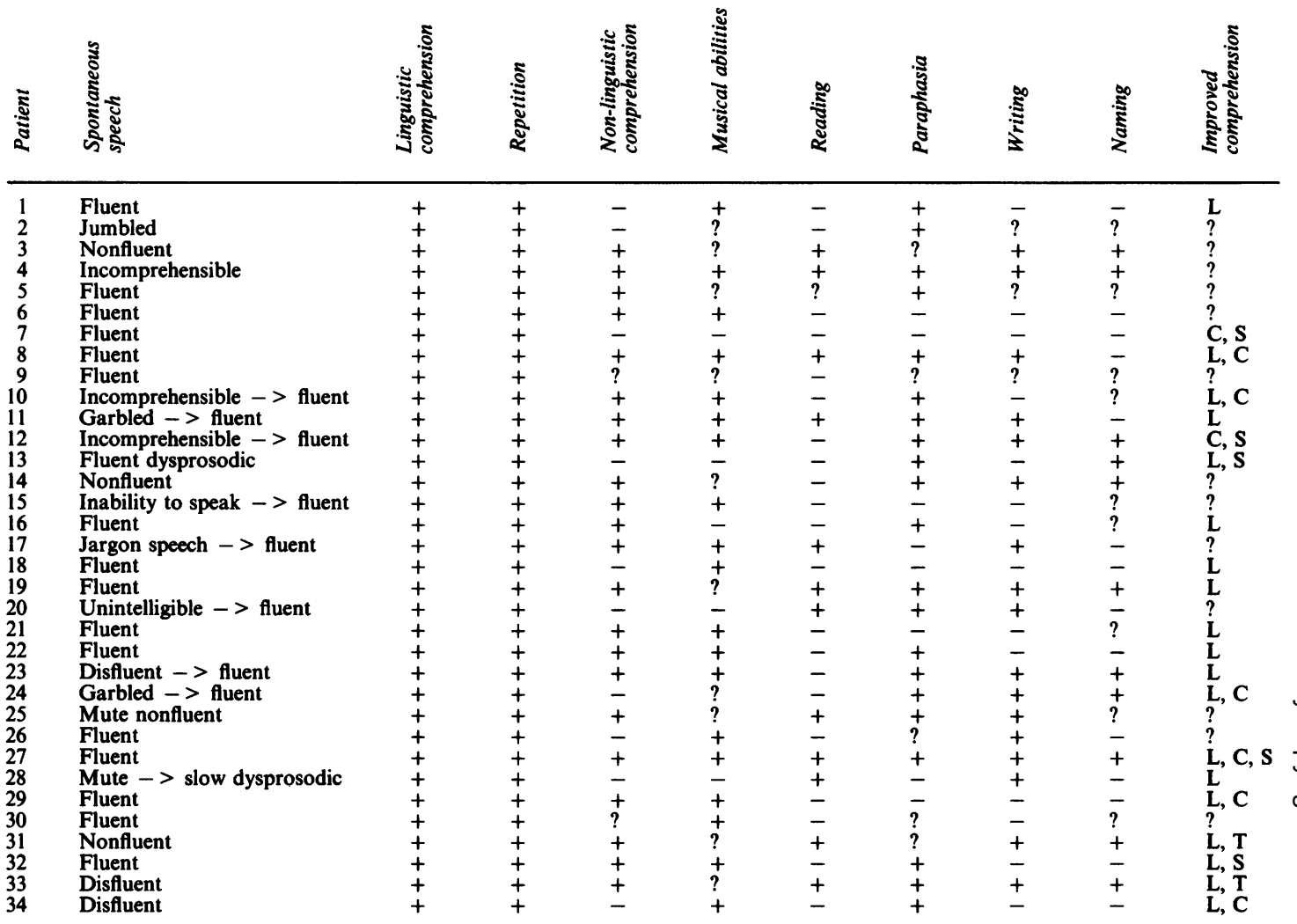

Key: C-contextual cues improved; L-lip reading improved; S-slowing speech improved; T-sign language improved; +-impaired;-—normal; ?-insufficient information.

iner, she was unable to match the written song title to the melody presented. Both copy-drawing and representational drawing (clock, house, daisy) revealed a lack of three dimensionality but were otherwise accurate in detail, spatial relationships, and orientation. The patient was especially bothered by the constant barrage of sounds from the television and preferred to have it turned off. She described spoken words as sounding like a "foreign language" and like "jabbering". Despite her recognition that spoken language sounded abnormal, she did not try to initiate communication through writing and would only do so if she was prompted by others. She did not think of herself as deaf and did not identify her deficit to others.

She was treated with haloperidol and transferred to a nursing home without any change in her language function. In October 1984, she was hospitalised and died suddenly while being treated for a urinary tract infection. Necropsy revealed cardiomegaly with mitral valve stenosis and left atrial enlargement with mural thrombus, massive bilateral pulmonary embolisation with infarction and pleural effusion.
The formalin-fixed brain weighed 1,240 grams. The left cerebral hemisphere was larger and longer than the right cerebral hemisphere. Softening of an area $4 \times 3 \times 3 \mathrm{~cm}$ was noted on palpation over the right temporal lobe. At the base of the brain, the vessels of the Circle of Willis were blue and elastic except for patches of yellow plaques in the midportion of the basilar artery and in the internal carotid artery. Sections of the brain showed three distinct cortical and subcortical infarctions and a fourth small infarction of the left anterior putamen. In the right cerebral hemisphere there was a cortical infarction of the superior parietal lobule which extended down to the anterior and posterior banks of the supramarginal gyrus and the rostral bank of the angular gyrus. The infarction extended laterally along the white matter and cortex of the superior, middle, and inferior temporal gyri almost to the temporal pole. Medially, this infarction extended to the posterior extreme capsule, claustrum, external capsule, and retrolenticular portion of the posterior internal capsule along the auditory and visual radiations. A second infarction was noted that began in the anterior bank of the left supramarginal gyrus. It extended 

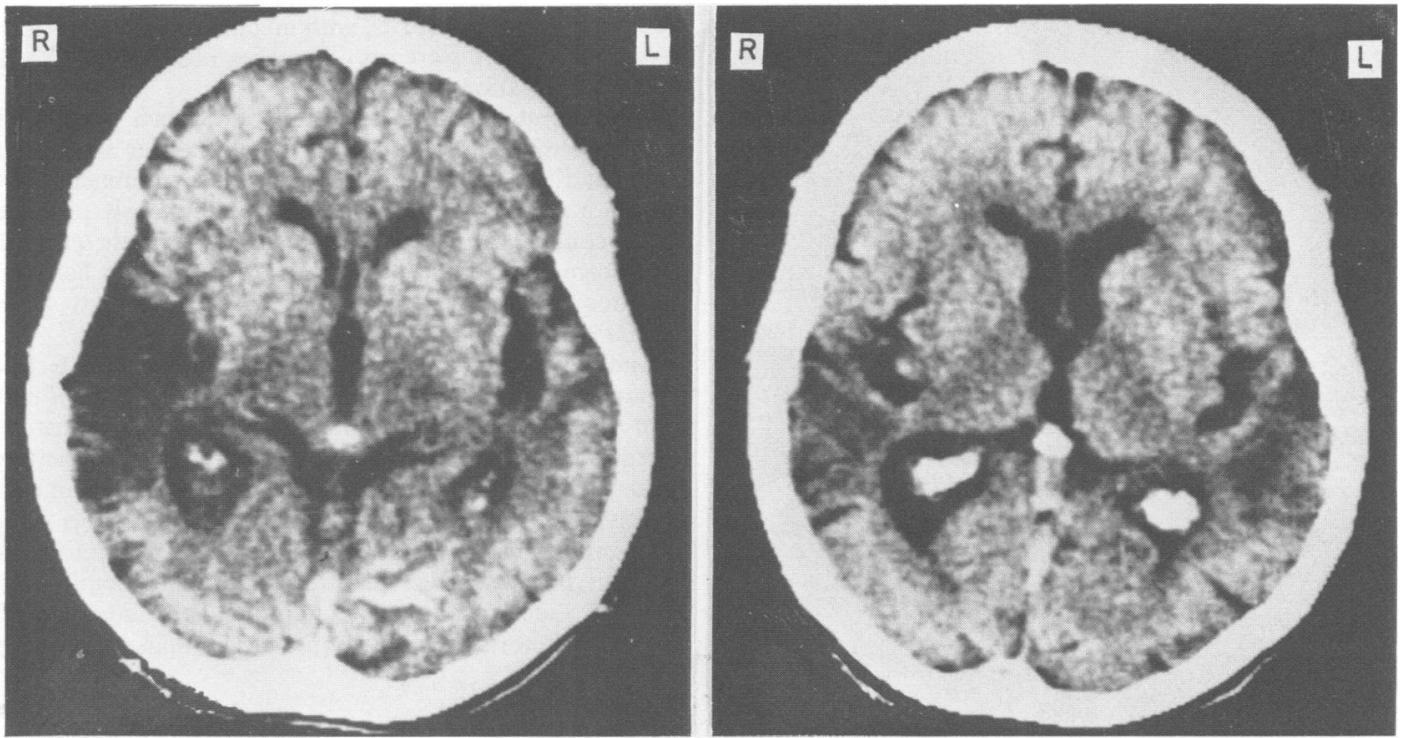

Fig 1 CT scan with contrast, of patient 1 following her psychiatric hospitalisation. The scan shows a large old right temporal lobe infarction and smaller left posterior temporo-parietal infarction. A small lacunar infarction in the left anterior limb of the internal capsule and a recent enhancing deep left occipital infarction are seen.

down to the parietal operculum, caudally and downward to Wernicke's area and anteriorly to Heschl's gyrus and the short transverse gyri. Medially, this infarction extended to the white matter between the temporal and parietal lobes and dipped down to the isthmus of the temporal lobe. A third infarction was noted in the deep white matter of the left occipital lobe. It extended from the calcarine fissure into the anterior bank of the lingular and superior bank of the cuneus gyrus. The infarctions showed shrunken granular tan to yellow discoloured tissue. Microscopic evaluation showed some suggestion of Alzheimer's disease.

\section{Patient 2}

A right-handed 62-year-old white female was admitted in April 1981, for the sudden onset of hearing difficulties. She developed slurred speech and was unable to understand speech sounds. She was able to write, comprehended what she read and responded appropriately to non-verbal sounds such as the doorbell. Her past medical history included rheumatic heart disease with mitral valve replacement in 1977, nephrectomy following renal artery embolus in 1976, right hemispheric infarction in 1975, gastrointestinal bleed in 1975 , and chronic atrial fibrillation.

On examination she was awake, alert and oriented. Neurological examination including visual fields was normal except for an equivocal right plantar response, ataxic gait and language dysfunction described below. Metabolic workup including collagen vascular screen was normal. A CT scan of the head and lumbar puncture showed no evidence of haemorrhage and the patient was anticoagulated. CT scans of the head were done on admission and fifteen days later, and showed a large old right temporo-parietal infarction with dilatation of the right lateral ventricle and a new enhancing left posterior temporo-parietal infarction.
Coronal reconstruction demonstrated right basal ganglionic extension and involvement of the left parietal and temporal operculum (fig 2). Pure tone air and bone conduction audiometry indicated mild to moderately severe sensorineural hearing loss bilaterally. Speech detection thresholds were $36 \mathrm{~dB} \mathrm{HL}$ for the right ear and $30 \mathrm{~dB}$ HL for the left ear. Speech discrimination could not be tested because of her speech comprehension deficit. Brainstem auditory and somatosensory evoked potentials were normal.

The patient displayed defective speech comprehension and repetition as well as impaired writing to dictation. Her spontaneous speech was fluent and articulate with appropriate use of meaningful and grammatically complex sentences. During a picture description task from the Boston Diagnostic Aphasia Examination (BDAE), most responses were single words and phrases, with no complete sentences evident. Communication through writing indicated a mild comprehension deficit. The results of selected subtests from the BDAE are shown in table 3. She was able to follow one-component commands when these were presented in writing, and was able to identify objects and actions as well as letters, colours, numbers, and geometric forms. However, she became confused unless the material was simple and concrete. Oral reading was intact for all levels of sentences and paragraph complexity. Reading comprehension was intact for simple sentences but was impaired for complex ideational material. Speech comprehension was facilitated by lip reading and contextual clues. She described both voices and non-speech sounds as "muffled". Despite reportedly being able to hear the telephone or the doorbell ring, the patient appeared not to hear the vacuum cleaner during speech evaluation. She was able to distinguish speech from music if spoken in the absence of background music. A follow-up speech evaluation three months later revealed some im- 


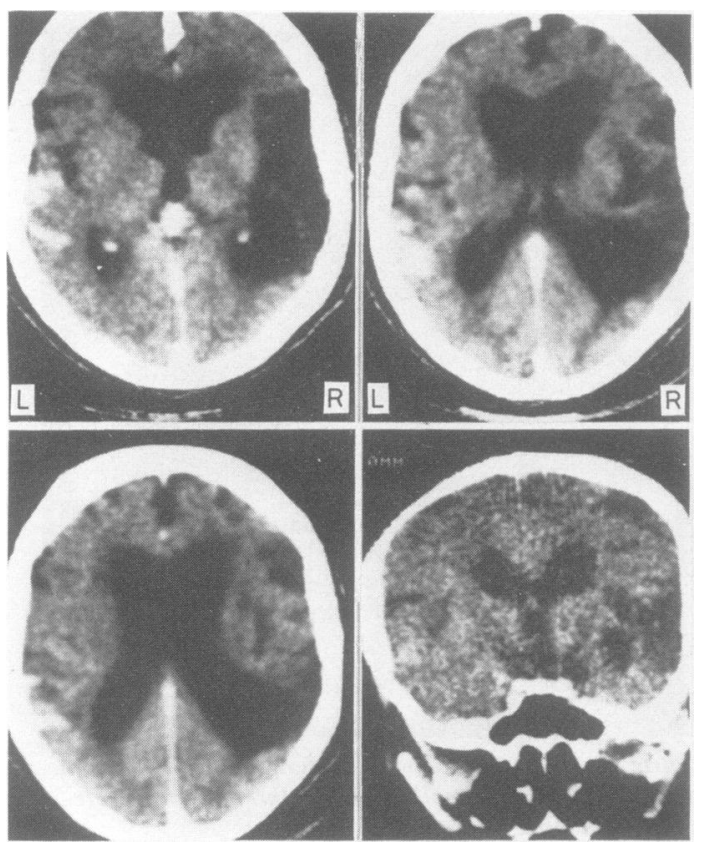

Fig 2 CT scan with contrast of patient 2 fifteen days after admission. The axial views show an old right temporoparietal infarction with dilitation of the right lateral ventricle. A recent enhancing left posterior temporo-parietal infarction is also seen. Coronal reconstruction demonstrates right basal ganglionic extension. (Left and right are reversed as compared with fig 1.)

provement in comprehension. Two months later, the patient suffered another cerebrovascular accident, and developed a non-fluent aphasia with a right hemiparesis.

\section{Patient 3}

A 50-year-old hypertensive, diabetic black female was seen in November 1973, for hearing difficulties noted during recovery from presumed herpes encephalitis. During the acute phase she had status epilepticus controlled with diazepam, diphenylhydantoin and phenobarbitone. Lumbar puncture results including herpes titres were consistent with the diagnosis of herpes encephalitis. EMI scan of the head and nuclear brain scan were normal. An EEG showed almost continuous epileptiform discharges originating in the right temporal region with spread to the left temporal and other regions. Occasional independent sharp waves were seen in the left temporal region. As the patient improved it was noted that she did not respond to the sound of clapping. She said that she felt deaf although she could hear noises. She was observed to orient herself in the direction of loud sounds. Neurologic exam was reported to be normal except for the language and auditory dysfunction described below. Audiological examination and auditory evoked potentials did not show evidence for peripheral dysfunction that would account for her deafness. Auditory evoked potentials were recorded while repetitive series of supra-threshold $10 \mathrm{kHz}$ tones were presented. The configuration of the evoked potentials obtained suggested that auditory stimuli produced a response in auditory cortex with no discernable hemispheric asymmetry. There were no differences observed due to the ear of presentation of the tones.

The patient demonstrated impaired speech comprehension, repetition, and writing to dictation. Her speech was fluent and normal. Reading aloud and comprehension of written material were normal. She spontaneously produced verbal comments and was able to ask appropriate questions with normal voice inflection. She correctly wrote her name upon request, although in one instance she incorrectly added an extra letter.

Auditory discrimination tapes were employed to test her response to non-linguistic sounds. A tape recording of common non-linguistic sounds was played and the patient was asked to identify the source of the sound from two pictures. Prior to testing of the sounds she was able to name the objects in the pictures used. The influence of possible verbal expressive difficulty was further eliminated by requiring her to point to the correct picture rather than identifying it verbally. Identification of non-linguistic sounds was markedly abnormal with response at less than chance level.

SUMMARY OF LANGUAGE AND AUDITORY TESTING All three patients demonstrated marked word deafness clinically with defective speech comprehension and repetition, and impaired writing to dictation. Auditory and language testing results, as well as additional clinical and demographic data are outlined in table 4.

Auditory testing in all three patients was abnormal. However, none of these patients was deaf, and these abnormalities were insufficient to account for their clinical deficits. Patient 2 , the only patient to undergo brainstem auditory evoked responses, had normal responses. Cortical auditory responses in patient 3 demonstrated bihemispheric responses without clear abnormalities.

Although patient 2 evidenced some mild reduction in speech fluency, all three patients had essentially fluent speech output. Naming was generally intact for patients 2 and 3 and was likewise functional for patient 1 , despite the inclusion of predominantly literal paraphasic errors. It is highly possible that differences in assessment methodology, as well as stringency in evaluating response accuracy, contributed to the variation in naming performance of the three patients. However, it is clear that none of these patients evidenced a marked anomia in spontaneous contextual speech output.

All patients evidenced problems in speech repetition and were unable to repeat connected speech. Patients 1 and 2 retained ability to repeat single words. They often appeared to rely on contextual cues and lip reading. The fact that patients 1 and 2 demonstrated relatively intact ability to "understand" isolated words, (WAB subtests: Auditory Word Recognition and Spoken Word/Written Word Matching; BDAE subtest: Word Discrimination), suggests that their deficits were more for comprehension of connected speech. Retained word recognition demonstrates that these tests may not be sufficiently discriminative for this disorder since the patient may benefit substantially from environmental and visual contextual cues. These patients may also substantiate the claim that word deafness represents a disorder of temporal auditory processing which would therefore be less apparent for single word recognition as opposed to connected speech. ${ }^{1535}$ 
All three patients had some impairment in non-linguistic sound comprehension. Patient 1 had normal ability to recognise environmental sounds and also demonstrated good ability to reproduce melodies modelled by the examiner. She was unable to generate melodies on her own, given the title, or to match titles to melodies presented. Patient 2 evidenced varied comprehension for non-linguistic sounds. Performance appeared to deteriorate with competing auditory input. Patient 3 was unable to identify non-linguistic sounds during both formal and informal assessment. Because of their associated auditory deficits, we feel that all three of these patients would appropriately be classified as having auditory agnosia using the scheme presented in table 1 .

Although reading comprehension was impaired in patients 1 and 2, it was strikingly superior to their auditory linguistic comprehension and provided the only means of facilitating interactive speech communication. Reading comprehension was intact in patient 3 . Writing was preserved in all three patients, both with respect to mechanical execution and grammatical competency.

The three patients gave different descriptions of their auditory perceptions. Whereas patient 1 described spoken language as "jabbering" patient 2 described both linguistic and non-linguistic sounds as "muffled". Moreover, although she was able to identify non-linguistic sounds, she reported that she was unable to "hear any voices". Patient 3 described all sounds as "noise".

Patients 1 and 2 developed symptoms following cerebrovascular events. Both patients had chronic atrial fibrillation and cardiac valvular abnormalities which were presumed sources of embolisation. The third patient developed symptoms following prolonged seizures and encephalitis.

All three patients had lesions of both temporal lobes and adjacent cortex. In patient 1 necropsy showed that the cortical and subcortical involvement was underestimated by CT scan. In patient 2 coronal reconstruction of CT scan showed subcortical extension to the right basal ganglia. Electroencephalography in patient 3 suggested bilateral injury extending beyond the temporal cortices.

In all three patients the sequence of cerebral injury responsible for their deficits could be determined using clinical and diagnostic testing. Both patients 1 and 2 had sequential cerebral injury with initial right hemispheric injury followed by left hemispheric injury, resulting in their cortical auditory disorders. In patient 1 , unilateral left hemispheric injury was suspected on clinical testing, but further diagnostic studies showed previously unsuspected contralateral injury. The third patient presented with bilateral cerebral injury.

Patients 2 and 3 did not demonstrate any associated psychiatric disturbances. Patient 1 was depressed following her cerebrovascular accident and then presented with psychosis one and a half years after the development of her auditory disorder. She also showed lack of insight into her deficit although she was able to characterise the quality of her auditory perceptions.

Patients 1 and 2 were seen at various stages following the onset of their symptoms. Patient 3 was lost for follow-up. Patient 1 was seen one and a half years after the onset of her symptoms. She was occasionally capable of single word comprehension. This was highly variable and insufficient to allow for verbal communication. Knowledge of subjects to be discussed, contextual cues and lip reading increased auditory comprehension. Patient 2 showed some recovery and was able to follow spoken single stage commands after two and a half months. She also benefited from contextual cues and lip reading.

\section{Discussion}

As described by Jerger and others, refined auditory testing demonstrates the existence of subtle auditory disturbances in patients with relatively normal pure tone audiometry. These disturbances include abnormalities of dichotic listening, click fusion, sound localisation, delayed auditory feedback and loudness discrimination. ${ }^{1821}$ Patients whose audiometric testing cannot account for their auditory comprehension deficits may be said to have an agnosia for sounds. When this deficit is limited to linguistic sounds it has been called pure word deafness or auditory verbal agnosia. By contrast, isolated agnosia for nonlinguistic sounds with retained normal language comprehension and function has rarely been reported. ${ }^{38}$ Patients with auditory agnosia for speech often display varying degrees of associated agnosia for nonlinguistic sounds including environmental sound recognition and deficits in appreciation and melody recognition. These patients can be described as having generalised auditory agnosia. ${ }^{30}$ The existence of separate central processing mechanisms for linguistic and non-linguistic sounds is best illustrated by Mott's patient. ${ }^{5}$ After her first stroke she had normal comprehension for non-linguistic sounds, but lost this after a second stroke. A patient reported by Albert et al quickly recovered spoken language comprehension, but significant impairment of non-verbal sound comprehension persisted. ${ }^{19}$ The term cortical deafness should probably be reserved for patients without brainstem or cochlear injury, who have markedly abnormal pure tone audiometry with deficits for all auditory stimuli. Many patients reported have demonstrated initial deafness for all sounds with variable recovery and eventual outcome marked by some degree of auditory agnosia. Clinical variation and improvement during recovery minimise the utility of the terms pure word deafness, auditory agnosia and cortical deafness and underscores their relatedness.

There has been great variability in the methods of testing of non-linguistic sound comprehension, ranging from informal testing by description of common environmental sounds to formal testing with a standard battery of sounds. Although informal testing may indicate normal comprehension of non-linguistic sounds, impairment may be revealed by more formal testing. ${ }^{35}$ Abnormal non-linguistic sound comprehension was described in 24 of 35 patients. The deficits ranged from total lack of sound perception to semantic identification errors. ${ }^{39}$ The variable recovery of non-linguistic sound comprehension and difficulties in 
classification of deficits are underscored by the fact that seven of these 24 patients were described as initially deaf for all sounds. Of the eleven with normal non-linguistic sound comprehension, five of nine who had descriptions of musical abilities had associated impairment of those abilities. A sixth patient, although able to hear and accurately describe nonlinguistic sounds, displayed abnormal reactions to warning sounds of danger. He narrowly missed being run over by a car although he acknowledged that he had heard the horn. ${ }^{9}$ These results suggest that the frequency of normal non-linguistic sound comprehension in word deafness has probably been overestimated in the past.

Many patients with cortical auditory disorders have associated impairment of musical abilities. Musical abilities, including singing, melody identification or rhythm reproduction, were described for 25 patients. There was great variability in the type and extent of musical evaluation and premorbid musical skills were often not described. Musical abilities were impaired in 20 of 25 patients. Linguistic and non-linguistic sound comprehension deficits were present in 14 of the 19 patients with impaired musical ability. Four of the five patients with normal musical ability demonstrated auditory comprehension deficits restricted to linguistic sounds. Thus musical ability impairment paralleled the severity of the auditory comprehension deficit.

Many authors include word deafness in discussions of aphasic disorders because the impaired auditory comprehension results in language impairment. The language impairment in word deafness is for comprehension of speech and is not characterised by spoken language deficits. These impairments in speech comprehension possibly reflect lower level auditory sensory discrimination and processing rather than a higher order perceptual deficit. The auditory comprehension deficits in word deafness contrast with the clearly semantic-associative auditory comprehension deficit seen in patients with transcortical sensory aphasia. Moreover, analogous visual deficits in optic radiation or primary visual cortex injury are not conceptualised as visual agnosias. Therefore, it is probably not consistent to conceptualise word deafness in the absence of other language impairments as an aphasia. This is not to deny that lesions in word deafness are often extensive, and may involve areas which do cause aphasia. The extent to which patients demonstrate both agnosia for sounds and primary sensory audiologic deficits remains unresolved.

Patients with word deafness usually display mild to moderate language abnormalities in other communication channels and may demonstrate components of aphasic syndromes. Conclusive characterisation of associated language deficits is difficult because of the lack of standardisation of language testing. Further difficulties result from variable recovery between the onset of deficits and initial evaluation. Associated language deficits are probably accounted for by the proximity of Wernicke's area to the auditory cortices. This is supported by recent studies of patients with otherwise typical Wernicke's aphasia, in which auditory comprehension was more impaired than visual comprehension. ${ }^{4041}$ These studies suggested that Wernicke's aphasia may be subdivided functionally by modality-biased comprehension impairments which correlate with different sites of injury.

Patients with word deafness share common features including aetiology, probable pathophysiology and anatomic localisation of injury, clinical presentation and course. Geschwind and others proposed that word deafness is caused by disconnection or isolation of Wernicke's area from auditory input. ${ }^{42}{ }^{43}$ Disconnection may be caused by bilateral primary auditory cortex injury or a strategically located left subcortical lesion which cuts off both ipsilateral and transcallosal auditory projections to Wernicke's area. Unilateral left subcortical lesions have been infrequently documented to cause word deafness. Bitemporal corticosubcortical lesions as seen in these three cases, however, are the more common cause. ${ }^{643}$ As seen in case 1 , the clinical picture may suggest a unilateral lesion. This highlights the importance of necropsy or CT scan for accurate anatomic localisation. These patients demonstrate that beyond bitemporal injury the amount of adjacent cortical and subcortical extension can vary greatly in patients with word deafness. The necropsy results in patient 1 , as in most previous necropsy studies of patients with word deafness, have demonstrated additional involvement of adjacent frontal, parietal and deep subcortical structures. ${ }^{4-81216203044}$ The role of these extended injuries and the variability of auditory and language deficits in cases of word deafness has not been specifically studied.

The average age of the patients reviewed was 47 years with a range of 13 to 76 years. Children with verbal auditory agnosia were excluded since they may represent a separate syndrome. ${ }^{45}$ Twenty-three patients were male and fourteen were female. Patients most frequently developed their deficits following a cerebrovascular event (30/37). Valvular heart disease or cardiac arrythmias were present in almost half of those with cerebrovascular accidents (14/30). This suggests that patients presenting with cortical auditory disorders should be evaluated for cardiac embolisation. Other less common aetiologies included encephalitis (3), trauma (2), seizures (3), and surgery (1).

Previous studies suggest that the sequence of cerebral injury predicts the clinical deficit. ${ }^{3146}$ The sequence of cerebral injury causing word deafness could 
be determined by clinical and laboratory tests in sixteen patients. The sequence was left hemisphere preceding right in seven and right prior to left in nine patients. Fifteen of these patients had descriptions of both linguistic and non-linguistic sound comprehension. Eleven patients had comprehension deficits for both linguistic and environmental sounds. Of these eleven, the sequence of cerebral injury was right to left in six and left to right in five. Among the four patients with only linguistic comprehension deficits the sequence of injury was right to left in three and left to right in the fourth. These results do not support claims that the sequence of injury is predictive of the clinical deficit.

Despite the clinical variability of performance on speech perception tasks, several factors have been noted to augment auditory verbal comprehension. Five patients reported improved comprehension with slowing of the speaker's rate of speech. This supports theories that word deafness is predominantly a problem of temporal resolution of speech. ${ }^{15}$ Our first two patients, in addition to eight others, demonstrated the benefit derived from knowledge of the subjects to be discussed or other contextual cues. Our first two patients, as well as nineteen other patients, improved their linguistic auditory comprehension when the speaker's face remained in view. However, one of these patients was only able to lip read if there was no vocalisation associated with the mouthing of words. ${ }^{23}$ This increase in comprehension has usually been attributed to lip reading. However, it has been suggested that patients benefit from amplification of visual affective components of speech. ${ }^{37}$ The improvement of auditory comprehension in word deafness through the use of patients' spared visual modality has led to attempts to utilise sign language in the rehabilitation of patients with word deafness. ${ }^{34} 36$

Our first two patients, like most patients, showed some improvement over time in their auditory comprehension. However, few patients recovered sufficiently to allow normal conversation. ${ }^{1826}$ This emphasises the need for intensive therapy utilising spared modalities to facilitate communication. Despite controversy concerning right hemispheric language capabilities one study has suggested that recovery of language function in aphasia following injury to the dominant hemisphere has been linked to the non-dominant hemisphere's ability to assume language function. ${ }^{47}$ The demonstration of bilateral lesions in patients with word deafness may preclude the possibility of significant recovery. ${ }^{13}$

Patients with word deafness usually recognise their deficit, as seen in our third patient; this may aid in rehabilitation. Our first patient, as well as a number of other patients demonstrated poor insight. The anatomical basis for this behaviour is not clear but may be anosognosia, seen after injury to the nondominant parietal lobe or a deficit similar to that seen in patients with Anton's syndrome or in Wernicke's aphasia. A number of patients have been thought to have psychiatric disorders when they initially presented with their cortical auditory disorders. This generally occurred because the diagnosis of word deafness was not entertained. The first patient we have reported presented with psychotic behaviour at age 75 , one and a half years after the onset of word deafness. The association between word deafness and psychiatric illness is uncommon although two patients without previous psychiatric illness developed significant depression following the onset of their illness. ${ }^{1236}$ The demonstration of a recent occipital infarction may have contributed to our first patient's deterioration, leading to her psychiatric hospitalisation. However, her psychiatric symptoms preceded her most recent infarction, having developed following her infarction of 1982. The possible contribution of pathologically documented Alzheimer's disease to this patient's psychiatric and auditory disturbances is unclear. ${ }^{48} \mathrm{Al}$ though it is difficult to separate the organic from reactive components that contributed to our patient's psychiatric disturbance, her hearing deficit may have played an important role. An association has been noted between post-lingual deafness and the development of paranoid psychoses in later life; age of onset, duration and severity of deafness were contributing factors. ${ }^{4950}$ The social isolation, sensory deprivation or distortion and communication disorder caused by the hearing deficit may all contribute to the development of psychosis. Intensive rehabilitation of patients with word deafness may ameliorate the consequences of functional deafness and decrease the development of psychosis. Two patients developed transient auditory hallucinations early in their course ${ }^{1013}$ Auditory hallucinations in word deafness may therefore be thought of as the auditory counterpart of the visual hallucinations seen in Anton's syndrome. ${ }^{10}$

Although Lichtheim's concept remains the clinical foundation for the diagnosis of word deafness, wider clinical experience and the introduction of sophisticated audiologic testing techniques necessitate a re-evaluation of his definition. The three new patients and 34 previously published cases of word deafness from the English literature were assessed for language and audiologic deficits. These data demonstrate a range of deficits not reflected in Lichtheim's original description. Although pure word deafness is a theoretical possibility, none of the patients reviewed with reported word deafness who have had formal testing of linguistic and non-linguistic and musical abilities have demonstrated "pure" word deafness. The common features that can be delineated in reported cases 
of pure word deafness, auditory agnosia and cortical deafness, suggest that the variation in auditory comprehension is a difference of degree rather than a manifestation of separate syndromes. The single syndrome is defined by the marked disparity between auditory verbal comprehension and other linguistic functions not seen in other aphasic patients and not by the occurrence of speech comprehension deficits, in isolation, as the name pure word deafness suggests. The term "word deafness" seems to be an overly specific description of the syndrome since all reported cases have exhibited additional auditory deficits. Despite its limitations, the term "word deafness" should be retained for naming this syndrome since word deafness is the most distinctive deficit on clinical exam.

The authors thank Dr MG Reyes for neuropathological evaluation of patient 1; L Horn, MA for speech and language evaluation of patient 2; Dr AW Kaszniak for neuropsychological testing and $\operatorname{Dr} \mathbf{J}$ Michael for evoked potential testing of patient 3; Dr RJ Foust for review of the CT scans; Dr CL Bartlett for helpful criticism; T Osofsky and Dr C Goetz for editorial assistance; C Buchman for preparation of the manuscript.

\section{References}

${ }^{1}$ Lichtheim L. On aphasia. Brain 1885;7:433-84.

${ }^{2}$ Benson FD. Aphasia, Alexia, and Agraphia. New York: Churchill Livingstone, 1979.

${ }^{3}$ Hecaen H, Albert M. Human Neuropsychology. New York: John Wiley and Sons, 1978.

${ }^{4}$ Mills CK. On the localisation of the auditory centre. Brain 1891;14:465-72.

${ }^{5}$ Mott FW. Bilateral lesion of the auditory cortical centre: complete deafness and aphasia. Br Med J 1907;2:310-5.

${ }^{6}$ Barrett AM. A case of pure word-deafness with autopsy. J Nerve Ment Dis 1910;37:73-92.

${ }^{7}$ Bramwell E. A case of cortical deafness. Brain 1927; 50:579-80.

${ }^{8}$ Le Gros Clark WE, Russell WR. Cortical deafness without aphasia. Brain 1938;61:373-83.

${ }^{9}$ Hemphill RE, Stengel E. A study on pure word-deafness. $J$ Neurol Psych 1940;3:251-62.

${ }^{10}$ Reinhold M. A case of auditory agnosia. Brain 1950; 73:203-23.

11 Jones J, Dinolt R. Pure word deafness. Laryngoscope 1952;62:194-203.

12 Wohlfart G, Lindgren A, Jernelius B. Clinical picture and morbid anatomy in a case of "pure word deafness". $J$ Nerv Ment Dis 1952;116:818-27.

${ }^{13}$ Ziegler DK. Word deafness and Wernicke's aphasia. Arch Neurol Psych 1952;67:323-31.

${ }^{14} \mathrm{~K}$ lein R, Harper J. The problem of agnosia in the light of a case of pure word deafness. J Ment Sci 1956; 102:112-20.

${ }^{15}$ Albert ML, Bear D. Time to understand: a case study of word deafness with reference to the role of time in auditory comprehension. Brain 1957;97:373-84.

${ }^{16}$ Kleist K. Sensory Aphasia and Amusia. New York: Pergamon Press, 1962:28-41.

${ }^{17}$ Tanaka Y, Taguchi K, Sakabe N, Igarashi E. Pure auditory agnosia associated with alteration of voice and personal character. Folia Phoniat 1964;17:185-94.

18 Jerger J, Weikers NJ, Sharbrough F, Jerger S. Bilateral lesions of the temporal lobe: A case study. Acta Otolaryngol [Suppl] (Stockh) 1969;258:1-51.

${ }^{19}$ Albert ML, Sparks R, von Stockert T, Sax D. A case study of auditory agnosia: linguistic and non-linguistic processing. Cortex 1972;8:427-43.

${ }^{20}$ Jerger J, Lovering L, Wertz M. Auditory disorder following bilateral temporal lobe insult: Report of a case. $J$ Speech Hear Dis 1972;37:523-35.

${ }^{21}$ Kanshepolsky J, Kelley JJ, Waggener JD. A cortical auditory disorder. Neurology (Minneap) 1973;23:699-705.

${ }^{22}$ Gazzaniga MS, Velletri Glass A, Sarno MT, Posner JB. Pure word deafness and hemispheric dynamics: A case history. Cortex 1973;9:136-43.

${ }^{23}$ Horenstein S, Bealmear K. Concerning the nature of word deafness. Trans Am Neurol Assoc 1973;98:264-7.

${ }^{24}$ Nagafuchi M, Suzuki J. Auditory agnosia due to incision of splenium corporis callosi. Acta Otolaryngol 1973; 76:109-13.

${ }^{25}$ Denes G, Semenza C. Auditory modality-specific anomia: Evidence from a case of pure word deafness. Cortex 1975;11:401-11.

${ }^{26}$ Goldstein MN, Brown M, Hollander J. Auditory agnosia and cortical deafness: Analysis of a case with three-year follow-up. Brain Lang 1975;2:324-32.

${ }^{27}$ Saffran EM, Marin OSM, Yeni-Komshian GH. An analysis of speech perception in word deafness. Brain Lang 1976;3:209-28.

${ }^{28}$ Earnest MP, Monroe MA, Yarnell PR. Cortical deafness: Demonstration of the pathologic anatomy by CT scan. Neurology (Minneap) 1977;27:1172-5.

${ }^{29}$ Shoumaker RD, Ajax ET, Schenkenberg T. Pure word deafness (Auditory verbal agnosia). Dis Nerv System 1977;38:293-9.

${ }^{30}$ Oppenheimer DR, Newcombe F. Clinical and anatomic findings in a case of auditory agnosia. Arch Neurol 1978;35:712-9.

${ }^{31}$ Dalla PM, Spinnler H, Vallar G. Pure word deafness and bilateral posterior perisylvian softenings. Arch Suisses Neurol Neurochi Psychiatry 1979;125:47-58.

${ }^{32}$ Michel F, Peronnet F, Schott B. A case of cortical deafness: Clinical and electrophysiological data. Brain Lang 1980;10:367-77.

${ }^{33}$ Parving A, Salomon G, Elberling C, Larson B, Lassen NA. Middle components of the auditory evoked response in bilateral temporal lobe lesions. Scand Audiol 1980;9:161-7.

${ }^{34}$ Kirshner HS, Webb WG. Selective involvement of the auditory-verbal modality in an acquired communication disorder: Benefit from sign language therapy. Brain Lang 1981;13:161-70.

${ }^{35}$ Auerbach SH, Allard T, Naeser M, Alexander MP, Albert ML. Pure word deafness: Analysis of a case with bilateral lesions and a defect at the prephonemic level. Brain 1982;105:271-300. 
${ }^{36}$ Doyle PJ, Holland AL. Clinical management of a patient with pure word deafness. In: Brookshire R, ed. Clinical Aphasiology 1982:138-46.

${ }^{37}$ Coslett HB, Brashear HR, Heilman KM. Pure word deafness after bilateral primary auditory cortex infarcts. Neurology (Cleveland) 1984;34:347-52.

${ }^{38}$ Spreen O, Benton AL, Fincham W. Auditory agnosia without aphasia. Arch Neurol 1965;13:84-92.

${ }^{39}$ Vignolo LA. Auditory agnosia: A review and report of recent evidence. In: Benton $\mathrm{AL}$, ed. Contributions to Clinical Neuropsychology. Chicago: Aldine Publishing Co, 172-231.

${ }^{40}$ Mohr JP, Hier DB, Kirshner HS. Modality bias in Wernicke's aphasia. Neurology (Minneap) 1978;28:395 (Abst.).

${ }^{41}$ Kirshner HS, Webb WG, Duncan GW. Word deafness in Wernicke's aphasia. J Neurol Neurosurg Psychiatry 1981;44:197-201.

${ }^{42}$ Geschwind N. Disconnection syndromes in animals and man. Brain 1965;88:237-94, 585-644.
${ }^{43}$ Goldstein MN. Auditory agnosia for speech ("Pure worddeafness"): A historical review with current implications. Brain Lang 1974;1:195-204.

${ }^{44}$ Brick JF, Frost JL, Schochet SS Jr, Gutmann L, Crosby TW. Pure word deafness: CT localization of the pathology. Neurology (Cleveland) 1985;35:441-2.

${ }^{45}$ Rapin I, Mattis S, Rowan AJ, Golden GG. Verbal agnosia in children. Dev Med Child Neurol 1977;19:192-207.

${ }^{46}$ Ulrich G. Interhemispheric functional relationships in auditory agnosia. Brain Lang 1978;5:286-300.

${ }^{47}$ Kinsbourne M. The minor cerebral hemisphere as a source of aphasic speech. Arch Neurol 1971;25:302-6.

${ }^{48}$ Grimes AM, Grady CL, Foster NL, Sunderland T, Patronas NJ. Central auditory function in Alzheimer's disease. Neurology (Cleveland) 1985;35:352-8.

${ }^{49}$ Cooper AF. Deafness and psychiatric illness. $\mathrm{Br} J$ Psychiatry 1976;129:216-26.

${ }^{50}$ Cooper AF, Garside RF, Kay DWK. A comparison of deaf and non-deaf patients with paranoid and affective psychoses. Br J Psychiatry 1976;129:532-8. 